\title{
Influence of Vasodilator Therapy on Prognosis of Acute Myocardial Infarction in the Aged Patients
}

\section{A Comparative Study between Vasodilator-treated Group and Group treated without Vasodilator}

\author{
Keiji Ueda, M.D., Junichiro Mifune, M.D., Hiroshi Inoue, M.D., \\ Masaya Sugrura, M.D., and Mototaka Murakami, M.D.
}

\begin{abstract}
SUMmary
Influence of vasodilator therapy on prognosis of acute myocardial infarction complicated by left heart failure (in Killip classes II and III) was studied in 22 aged patients (mean age; 75.7 years). The patients were retrospectively divided into 2 groups: Group I; 12 patients were treated with isosorbide dinitrate and/or chlorpromazine and Group II; 10 patients were treated with other conventional medical measures. Initial hemodynamic changes on admission were not significantly different between 2 groups.

With these treatments mortality rate within 2 weeks of treatment was lower in Group I than in Group II $(p<0.01)$, however, cumulative cardiac mortality rate within 18 months did not differ significantly. The present study demonstrated beneficial influence of vasodilator therapy on early prognosis in aged patients, but failed to show prolonged influence on later mortality.
\end{abstract}

\section{Additional Indexing Words:}

Isosorbide dinitrate Chlorpromazine

\begin{abstract}
$\mathrm{T}$ recent years, growing interest has been focussed on the application of vasodilators to the treatment of acute myocardial infarction (AMI) complicated by pump failure. ${ }^{1-3)}$ Beneficial acute hemodynamic effects of several vasodilating agents have been demonstrated and it has been suggested that vasodilator therapy favourably influences short-term prognosis in patients with severe pump failure in AMI.4) However, to the best of our knowledge, there has been no report in which effects of vasodilator therapy on early and late prognosis of AMI was compared to that in control group, not treated with vasodilator. Furthermore, the effect of vasodilator therapy in aged

From the Division of Cardiology, Department of Medicine, Tokyo Metropolitan Geriatric Hospital, Tokyo

Address for reprint: Keiji Ueda, M.D., Division of Cardiology, Tokyo Metropolitan Geriatric Hospital, 35-2 Sakae-cho, Itabashi-ku, Tokyo 173, Japan.

Received for publication May 29, 1979.
\end{abstract}


Table I. Clinical data and hemodynamic findings

\begin{tabular}{c|c|c|l|c|c|c|c}
\hline No. & Age & Sex & Infarct location & $\begin{array}{c}\text { Previous } \\
\text { infarct }\end{array}$ & $\begin{array}{c}\text { Duration } \\
\text { between AMI } \\
\text { and admission }\end{array}$ & $\begin{array}{c}\text { Killip's } \\
\text { classifi- } \\
\text { cation }\end{array}$ & $\begin{array}{c}\text { Chest } \\
\text { X-ray }\end{array}$ \\
\hline 1 & 69 & $\mathrm{M}$ & Int & Yes & 9 days & III & IV \\
2 & 68 & $\mathrm{~F}$ & Inf & Yes & $<1$ day & III & IV \\
3 & 77 & $\mathrm{M}$ & Ant, Lat & No & 12 days & III & III \\
4 & 79 & $\mathrm{~F}$ & Inf & No & 16 days & III & IV \\
5 & 77 & $\mathrm{~F}$ & Ant & Yes & $<1$ day & III & IV \\
6 & 71 & $\mathrm{~F}$ & Inf & No & 2 days & III & IV \\
7 & 78 & $\mathrm{~F}$ & Ant, Lat, Inf & No & 2 days & III & IV \\
8 & 68 & $\mathrm{~F}$ & Subend & No & $<1$ day & III & IV \\
9 & 71 & $\mathrm{~F}$ & Subend & No & $<1$ day & III & III \\
10 & 80 & $\mathrm{~F}$ & Anterosep & Yes & $<1$ day & III & IV \\
11 & 80 & $\mathrm{~F}$ & Anterosep & No & 7 days & II & II \\
12 & 74 & $\mathrm{~F}$ & Subend & Yes & 2 days & II & II
\end{tabular}

Abbreviations: Inf; inferior infarction, Ant; anterior infarction, Lat ; lateral infarction, Anterosep; anteroseptal infarction, Subend; subebdocardial infarction, + ; succumbed, ( ); non-cardiac

patients with AMI has not been reported.

This study compares the early and late prognosis in aged patients with AMI treated with vasodilator to that in hemodynamically comparable patients treated without vasodilator.

\section{Materials and Methods}

Patient population and clinical data:

The study group consisted of 22 aged patients (age ranged from 68 to 83 years, mean; 75.7 years), who were admitted to the coronary care unit of Tokyo Metropolitan Geriatric Hospital during the period between January, 1976 to December, 1977. The patients were selected consecutively from aged patients with AMI in CCU who showed clinical signs of left heart failure (in Killip classes II and III) ${ }^{5}$ ) and in whom hemodynamic evaluation was made on admission. Patients with no sign of heart failure (in Killip class I) or in shock (in Killip class IV) and patients under age of 60 years were excluded from the study.

Diagnosis of AMI was made on the basis of followings; 1) a history of chest pain or other cardiac symptoms consistent with cardiac ischemia (unless the clinical setting did not permit adequate evaluation of symptoms), 2) diagnostic elevation of serum creatine phosphokinase levels, and 3) serial electrocardiographic changes consistent with the diagnosis.

Clinical data of the patients are summarized in Tables I and II. Severity of left heart failure was assessed clinically on admission and is expressed by Killip's classification. ${ }^{51}$ Roentgenologic findings of left heart failure on admission are classified as follows: class I; normal pulmonary vascular shadows, class II; slight hilar congestion and intensified vascular shadows in the upper lung, class III; class II+ 
in Group I (vasodilator-treated group)

\begin{tabular}{|c|c|c|c|c|c|}
\hline \multirow{2}{*}{$\begin{array}{l}\text { Cardiac index } \\
\left(\mathrm{L} / \mathrm{min} / \mathrm{M}^{2}\right)\end{array}$} & \multirow{2}{*}{$\begin{array}{l}\text { Pulmonary } \\
\text { artery pressure } \\
\text { (mmHg) }\end{array}$} & \multicolumn{2}{|l|}{ Vasodilator } & \multicolumn{2}{|r|}{ Mortality } \\
\hline & & Drugs & Duration & $\leqq 2$ weeks & 2 weeks $\sim 18$ months \\
\hline 4.01 & $60 / 20$ & Chlorpromazine & 1 day & & \\
\hline 2.42 & $16 / 9$ & ISD & 90 days & & ${ }_{\text {Pump failure }}^{+}$ \\
\hline 2.37 & $32 / 14$ & ISD & 8 days & & \\
\hline 2.40 & $48 / 22$ & ISD & 18 days & & ${ }^{+}$ \\
\hline 1.85 & $48 / 22$ & ISD & 18 days & & \\
\hline 2.08 & $54 / 30$ & ISD & 12 days & & $\stackrel{+}{\text { Reinfarction }}$ \\
\hline 1.57 & $34 / 22$ & ISD & 5 days & & \\
\hline 2.45 & $68 / 24$ & Chlorpromazine & 1 day & & \\
\hline 2.66 & $45 / 27$ & Chlorpromazine, ISD & 5 days & & + \\
\hline 1.52 & $46 / 22$ & ISD & 4 days & & Pump failure \\
\hline 2.28 & $24 / 14$ & ISD & 7 days & & + \\
\hline 2.42 & $21 / 10$ & ISD & 11 days & & eur \\
\hline
\end{tabular}

cause of death.

intensified peripheral vascular shadows, class IV; class III + pleural effusion, marked pulmonary congestion, edema, and cardiomegaly.

Six patients were admitted within 24 hours after the onset of AMI, 4 patients between 24 hours and 48 hours, 2 within 3 days, 5 between 5 days and 1 week, and 4 within 2 weeks.

The patients were divided retrospectively into 2 groups as described below.

\section{Methods:}

Hemodynamic study was performed soon after the admission in all cases. Right atrial, pulmonary arterial, and usually pulmonary capillary pressures were monitored with the balloon-tipped floatation (Swan-Ganz) catheter, ${ }^{6,7)}$ arterial pressure was monitored usually through a cannula inserted into the peripheral artery. In a few patients, arterial pressure was measured with a sphyngomanometer. Cardiac output was measured by the thermodilution technique ${ }^{\left(6,{ }^{2}\right)}$ using the same catheter. Pulmonary arterial end-diastolic pressure was defined as left ventricular filling pressure (LVFP) and following hemodynamic parameters were calculated; stroke volume index (SVI) $=\mathrm{SV} /$ body surface area $\left(\mathrm{ml} / \mathrm{M}^{\mathbf{2}}\right)$; stroke work index $=\mathrm{SVI} \times($ mean arterial pressure $-\mathrm{LVFP}) \times 0.0144\left(\mathrm{~g}-\mathrm{m} / \mathrm{M}^{2}\right)$.

Twelve patients (Group I; case 1-case 12, Table I) were treated either with isosorbide dinitrate (ISD) (9 cases) or chlorpromazine (2 cases), or chlorpromazine followed by ISD ( 1 case). When ISD was administered, usually $5 \mathrm{mg}$ of ISD was administered sublingually every 4 hours or 10 to $15 \mathrm{mg}$ of ISD orally every 6 hours. When chlorpromazine was used, dose of 5 to $10 \mathrm{mg}$ was injected intramuscularly. Drugs and duration of the administration are shown in Table I. Duration of vasodilator therapy listed in Table $I$ indicates the period in which drug administration was rigidly controlled. Digitalis and/or diuretics were used in 5 patients, usually immediately after the admission and prior to hemodynamic study and the institution of vasodilator therapy, and antiarrhythmic agents in 2 patients. 
Table II. Clinical data and hemodynamic

\begin{tabular}{c|c|c|c|c|c|c|c}
\hline No. & Age & Sex & Infarct location & $\begin{array}{c}\text { Previous } \\
\text { infarct }\end{array}$ & $\begin{array}{c}\text { Duration } \\
\text { between AMI } \\
\text { and admission }\end{array}$ & $\begin{array}{c}\text { Killip's } \\
\text { classifi- } \\
\text { cation }\end{array}$ & $\begin{array}{c}\text { Chest } \\
\text { X-ray }\end{array}$ \\
\hline 13 & 67 & F & Int & Yes & 3 days & III & III \\
14 & 87 & M & Subend & No & $<$ l day & III & III \\
15 & 76 & M & Inf, Lat & Yes & 2 wecks & III & III \\
16 & 80 & F & Ant & No & 5 days & III & IV \\
17 & 75 & F & Anterosep & No & $<1$ day & III & IV \\
18 & 83 & F & Lat & No & 5 days & III & III \\
19 & 78 & F & Subend & Yes & 5 days & III & II \\
20 & 77 & F & Anterolat & No & 7 days & II & II \\
21 & 74 & M & Inf & No & 3 days & II & II \\
22 & 76 & F & Subend & No & 2 days & II & II \\
& & & & & & &
\end{tabular}

Abbreviations, as in Table $\mathrm{I}$.

Ten patients (Group II; case 13-case 22, Table II), who did not receive vasodilator therapy, served as the control group. Reasons for not applying vasodilator in these patients included followings; lower arterial blood pressure on admission in 3 patients, associated disorders which prevented the administration of ISD tablets sublingually or orally in 5 patients, and relatively mild symptoms and signs of pulmonary congestion on admission which did not prompt the use of vasodilator therapy in 2 patients. Instead these patients were treated with conventional medical therapeutic measures, including digitalis, diuretics and/or antiarrhythmic agents, when indicated.

The patients were closely followed during post-coronary care and after discharge, but without any definite protocol of treatment. Mortality rate in these 2 groups were calculated as follows; 1) early mortality rate, as defined as mortality rate within 2 weeks of treatment after the admission, and 2) late mortality rate, as defined as mortality beyond 2 weeks after the admission up to 18 months after the onset of AMI. Cumulative mortality rate was calculated as a sum of early and late mortality rate. Causes of death were identified from the hospital records and autopsy findings, and mortality due to cardiac origin was separately evaluated from non-cardiac mortality.

\section{Results}

Clinical background and hemodynamic changes in 2 groups:

Age ranged from 68 to 80 years $(74.3 \pm 1.4$ years, mean $\pm S E$ ) in Group I and from 67 to 83 years $(77.3 \pm 1.7$ years $)$ in Group II, and they were not significantly different (NS). Previous infarction was present in 5 patients $(41.6 \%)$ of Group I and 3 patients $(30 \%)$ of Group II (NS). Location of AMI did not differ significantly between 2 groups; anteroseptal or anterior 
findings in Group II (control group)

\begin{tabular}{|c|c|c|c|c|}
\hline \multirow{2}{*}{$\begin{array}{c}\text { Cardiac index } \\
\left(\mathrm{L} / \mathrm{min} / \mathrm{M}^{2}\right)\end{array}$} & \multirow{2}{*}{$\begin{array}{l}\text { Pulmonary } \\
\text { artery pressury } \\
(\mathrm{mmHg})\end{array}$} & \multirow{2}{*}{$\begin{array}{l}\text { Reasons for not } \\
\text { using dilator }\end{array}$} & \multicolumn{2}{|c|}{ Mortality } \\
\hline & & & $\leqq 2$ weeks & 2 weeks $\sim 18$ months \\
\hline 2.14 & $68 / 32$ & Nausea & Pump failure & \\
\hline 1.82 & $53 / 27$ & Lower BP & Electromechanical & \\
\hline 1.81 & $39 / 21$ & Dysphagia duc to GVD & dissociation & \\
\hline 1.49 & $50 / 22$ & Nausea & Pump failure & (Pneumonia) \\
\hline 2.40 & $48 / 25$ & Lower BP & ${ }^{+}{ }^{+}$ & \\
\hline 2.30 & $28 / 12$ & Pneumonia & & + \\
\hline 2.16 & $26 / 10$ & Preumonia & & (Pneumonia) \\
\hline 3.01 & $29 / 10$ & Mild symptoms & Ventricular fibrill & \\
\hline 2.94 & $34 / 12$ & Lower BP & & \\
\hline 1.80 & $28 / 11$ & Mild symptoms & & \\
\hline
\end{tabular}

Table III. Comparison of hemodynamic changes between Group I and Group II

\begin{tabular}{l|c|c|c}
\hline \multicolumn{1}{c|}{ No. of patients } & Group I & Group II & \\
\cline { 2 - 3 } & 12 & 10 & \\
\hline Age (yrs.) & $74.3 \pm 1.4$ & $77.3 \pm 1.7$ & NS \\
Heart rate (bpm) & $97.3 \pm 4.6$ & $90.5 \pm 6.3$ & NS \\
Cardiac index (L/min/M $\left./ \mathrm{M}^{2}\right)$ & $2.33 \pm 0.19$ & $2.18 \pm 0.15$ & NS \\
LVFP (mmHg) & $19.5 \pm 1.8$ & $18.2 \pm 2.5$ & NS \\
Systolic arterial pressure (mmHg) & $135.0 \pm 8.5$ & $119.6 \pm 4.2$ & NS \\
Mean arterial pressure $(\mathrm{mmHg})$ & $100.1 \pm 5.0$ & $90.8 \pm 4.1$ & NS \\
Stroke work index $\left(\mathrm{g} \cdot \mathrm{m} / \mathrm{M}^{2} / \mathrm{beat}\right)$ & $28.1 \pm 3.1$ & $25.6 \pm 3.0$ & NS
\end{tabular}

infarction was observed in 6 patients $(50 \%)$ in Group I, while in 3 patients $(30 \%)$ in Group II, posterior infarction was noted in 3 patients $(25 \%)$ in Group $I$ and in 2 patients $(20 \%)$ in Group II. Mean duration between the onset of AMI and the admission to the CCU was 4.5 days in Group $I$ and 5.4 days in Group II (NS).

Hemodynamic changes on admission in 2 groups are summarized and compared in Table III. Heart rate in Groups I and II were $97.3 \pm 4.3$ and $90.5 \pm 6.3 \mathrm{bpm}$ (NS), respectively. Cardiac index tended to be slightly higher in Group I $\left(2.33 \pm 0.19 \mathrm{~L} / \mathrm{min} / \mathrm{M}^{2}\right)$ than in Group II $(2.18 \pm 0.15)$, but this difference was not statistically significant. LVFP did not differ significantly between Group I $(19.5 \pm 1.8 \mathrm{mmHg})$ and Group II $(18.2 \pm 2.5 \mathrm{mmHg})$. Systolic arterial and mean arterial pressure tended to be slightly higher in 
Table IV. Comparison of mortality rate between Group I and Group II

\begin{tabular}{|c|c|c|c|c|}
\hline & \multicolumn{2}{|c|}{ Mortality within 2 weeks } & \multicolumn{2}{|c|}{$\begin{array}{c}\text { Cumulative mortality } \\
\text { within } 18 \text { months }\end{array}$} \\
\hline & Group I & Group II & Group I & Group II \\
\hline Number of patients & 12 & 10 & 12 & 10 \\
\hline Killip class II & $0 / 2$ & $1 / 3$ & $1 / 2$ & $1 / 3$ \\
\hline Killip class IIII & $0 / 10$ & $4 / 7$ & $4 / 10$ & $6 / 7$ \\
\hline Total mortality & $\begin{array}{l}0 / 12 \\
(0 \%)\end{array}$ & $\begin{array}{c}5 / 10 \\
(50 \%)\end{array}$ & $\begin{array}{c}5 / 12 \\
(41.7 \%)\end{array}$ & $\begin{array}{c}7 / 10 \\
(70 \%)\end{array}$ \\
\hline \multirow[t]{2}{*}{ Total cardiac mortality } & $\begin{array}{l}0 / 12 \\
(0 \%)\end{array}$ & $\begin{array}{c}5 / 10 \\
(50 \%)\end{array}$ & $\begin{array}{c}4 / 12 \\
(33.3 \%)\end{array}$ & $\begin{array}{c}5 / 10 \\
(50 \%)\end{array}$ \\
\hline & \multicolumn{2}{|c|}{$\mathrm{p}<0.01$} & \multicolumn{2}{|c|}{ NS } \\
\hline
\end{tabular}

Group I (135.5 \pm 8.5 and $100.1 \pm 5.0 \mathrm{mmHg}$, respectively) than in Group II $(119.6 \pm 4.2$ and $90.8 \pm 4.1 \mathrm{mmHg})$, but differences were not statistically significant.

These results indicate that these 2 groups can be regarded to be comparable in terms of clinical background and hemodynamic changes. These findings support the validity of the assumption that Group II served as the control group for Group I.

\section{Comparison of mortality rate:}

Mortality and cause of death are indicated in Tables I and II, and early and cumulative mortality rate in 2 groups are compared in Table IV.

Five patients died within 2 weeks of the treatment with mortality rate of $50 \%$ in Group II, while all patients in Group I survived this period. Causes of death in Group II were pump failure in 3, sudden development of electromechanical dissociation in 1 and ventricular fibrillation immediately after the discharge from $\mathrm{CCU}$ in 1.

Relation between hemodynamic changes and early mortality is illustrated in Fig. 1. While all of 8 patients in Group $I$ in whom LVFP exceeded $18 \mathrm{mmHg}$ (in Forrester subsets II and IV) ${ }^{8}$ survived 2 weeks after admission, 4 patients out of 5 in Group II with comparable elevation of LVFP died in this period.

During the period from 2 weeks after the admission to 18 months 5 patients in Group I died, 3 of them died from pump failure, 1 from recurrent attack of AMI and 1 from penumonia, while in Group II 2 patients died from pneumonia, but no further cardiac death was noted in Group II during this follow-up period. Therefore, cumulative cardiac mortality rate within 18 months was 33.3\% (4 deaths in 12 patients) in Group I and 50\% (5 deaths 


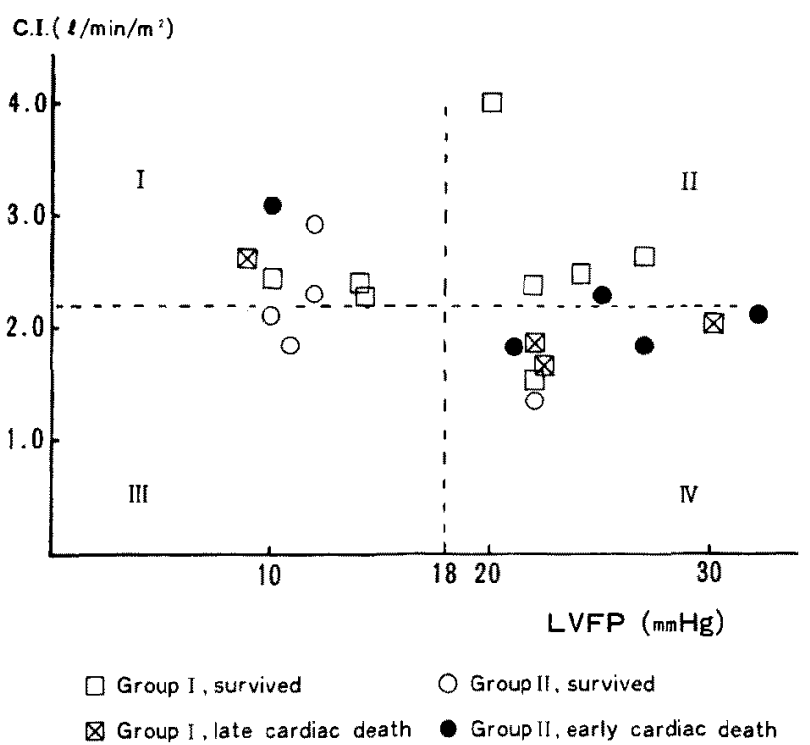

Fig. 1. Hemodynamic spectrum and prognosis in Group I and Group II. (details, see text)

in 10 patients) in Group II. This difference was not statistically significant. Relation between hemodynamic changes and late cardiac mortality is also illustrated in Fig. 1. Three out of 4 patients who died from pump failure or reinfarction showed elevated LVFP and decreased cardiac index (in Forrester subset IV).

\section{Discussion}

It has been shown that vasodilating agents can improve cardiac performance in patients with AMI complicated by pump failure. Hemodynamic improvement has been documented by the administration of sodium nitroprusside ${ }^{9), 10)}$ phentolamine, ${ }^{11), 12)}$ nitrates, ${ }^{10), 13(-17)}$ and chloropromazine. ${ }^{18), 19)}$ These favourable effects of vasodilator are primarily related to either or both of the decrease in arteriolar resistance (afterload reduction) and the increase in venous capacitance resulting in the decrease in venous return to the heart (preload reduction).

Effects of vasodilators on myocardial metabolism and on regional myocardial blood flow have been extensively studied ${ }^{20)-27)}$ and conflicting results have been reported. It has been also suggested that vasodilators may be potentially deleterious. ${ }^{14,24), 281}$ Relief of pulmonary congestion by nitrates is sometimes accompanied by a significant fall in cardiac output and systemic 
blood pressure. ${ }^{14), 28}$ ) An increase in ST-segment elevation with a decrease in myocardial blood flow in ischemic myocardium in experimental animals has been reported following sodium nitroprusside. ${ }^{24}$ Influence of these adverse effects of vasodilators on early and late prognosis of patients with AMI has not been fully elucidated.

As to the influence of vasodilator therapy on prognosis of AMI complicated by pump failure, Chatterjee et al $^{4)}$ reported vasodilator therapy could improve immediate prognosis in these patients, but the late prognosis remained unfavourable. However, the efficacy of any drug therapy ideally should be evaluated clinically from the results of prospective randomized, controlled trials, although it can not be easily accomplished, if not impossible, in patients with AMI. From this point of view, it can be stated that the effects of vasodilator therapy on prognosis of AMI complicated by pump failure have been inconclusive.

In the present study, although it is a retrospective study, not a prospective randomized study, the influence of vasodilator therapy on early and late prognosis can be compared to the mortality rate in a group of patients with clinically and hemodynamically comparable background who were teated with other therapeutic measures. Although this study is limited to aged patients, and to a relatively small number of patients with clinical signs of heart failure (in Killip class II and class III), effects of vasodilator therapy on early prognosis is clearly demonstrated by the results of no immediate mortality in Group I compared to $50 \%$ mortality in Group II. In the present study, patients with AMI in Killip class I and IV were excluded, because in the former vasodilator therapy is not indicated and in the latter vasodilator therapy alone, especially with ISD, has been shown to be less efficacious. ${ }^{3{ }^{2} \text {, }}$ )

Treatment of left heart failure in 10 patients of Group II with conventional, medical therapeutic measures including oxygen inhalation, diuretics, and digitalis, but with no vasodilating agent may not involve ethical problems and these approaches in these patients during the period when the present study was performed may be validated from following reasons; 1) favourable influence of vasodilator therapy on prognosis of AMI complicated by pump failure has not been definitely confirmed and 2) these patients individually had a basis against the use of vasodilator, especially of ISD, as listed in Table II. Some cases may demand further comments; in cases 6 and 7 ISD was not used, because difficulty in evaluation of improvement of mild symptoms of left heart failure was anticipated by the association of pneumonia with AMI, and ISD or chlorpromazine was not administered to patients with relatively lower systolic arterial pressure, as cases 2, 5, and 9.

Although the extent of influences of these associated factors in Group II 
on early prognosis could not be evaluated, 4 patients in Group II died from severe pump failure, probably suggesting the ineffectiveness of conventional medical measures in this situation. In this regard, possible influence of slightly lower arterial pressure and cardiac indices in Group II, although not statistically significant, on the result of more unfavourable early prognosis can not be denied.

The present study failed to show a definitely favourable prognosis in Group II, when patients who survived 2 weeks after the admission were followed up to 18 months. Cumulative cardiac mortality rate in Group I $(33.3 \%)$ did not differ significantly from that in Group II $(50 \%)$. This result may be in accordance with previous report on late mortality by Chatterjee et al." Although any definite conclusion may be premature from the results obtained in relatively small number of aged patients in the present study, it appears likely that refractory heart failure in these patients as the consequence of extensive myocardial necrosis can ensue, in spite of temporary relief of pulmonary congestion by vasodilating agents in acute stage of AMI. This may imply that vasodilating agents do not substantially reduce the extent of infarcted myocardium, and more rigidly controlled regimen of vasodilators for more extended period of time after AMI may improve the late prognosis in light of the effects of vasodilator therapy in chronic heart failure, ${ }^{29,30)}$ although it remains speculative in patients with AMI.

Aged patients more frequently develop atypical symptoms at the onset of AMI than younger patients. ${ }^{31,32)}$ This sometimes makes early clinical recognition of AMI difficult, and causes a delay in the admission and institution of the definitive therapy for left heart failure as seen in some cases of the present study. It has been also documented that severe complications are more common and mortality rate is higher in aged patients with AMI.31),32) In this regard, the results of favourable influence of vasodilator therapy on early prognosis of aged patients with AMI and left heart failure may be promising and may support the wide use of vasodilators, if indicated. But further efforts to improve the late mortality of AMI is mandatory.

\section{REFERENCES}

1. Chatterjee K, Parmley WW: Vasodilator treatment for acute and chronic heart failure. Brit Heart J 39: 706, 1977

2. Cohn JN, Franciosa JA: Vasodilator therapy of cardiac failure. New Engl J Med 297: $27,254,1977$

3. Mason DT: Alterload reduction and cardiac performance. Physiologic basis of systemic vasodilators as a new approach in treatment of congestive heart failure. Am J Med 65: 106, 1978

4. Chatterjee K, Swan HJC, Kanshik VS, Jobin G, Magnusson P, Forrester JS: Effects of va- 
sodilator therapy for severe pump failure in acute myocardial infarction on short term and late prognosis. Circulation 53: 797, 1976

5. Wolk MJ, Scheidt S, Killip T: Heart failure complicating acute myocardial infarction. Circulation 45: 1125, 1972

6. Ganz W, Donoso R, Marcus HS, Forrester JS, Swan HJC: A new technique for measurement of cardiac output by thermodilution in man. Am J Cardiol 27: 392, 1971

7. Forrester JS, Ganz W, Diamond G, McHugh T, Chonette DN, Swan HJC: Thermodilution cardiac output measurement with a single flow directed catheter. Am Heart J 83: 306, 1972

8. Forrester JS, Diamond G, Chatterjee K, Swan HJC: Medical therapy of acute myocardial infarction by application of hemodynamic subsets. New Engl J Med 295: 1356, 1976

9. Franciosa JA, Guiha NH, Limas GJ, Rodriguera E, Gohn JN: Improved left ventricular function during nitroprusside infusion in acute myocardial infarction. Lancet 1: 650, 1972

10. Armstrong PW, Walker DC, Burton JR, Parker JO: Vasodilator therapy in acute myocardial infarction. A comparison of sodium nitroprusside and nitroglycerin. Circulation 52: 1118, 1975

11. Walinsky P, Chatterjee K, Forrester J, Parmley WW, Swan HJC: Enhanced left ventricular performance with phentolamine in acute myocardial infarction. Am J Cardiol 33: 37, 1974

12. Gould L, Reddy CVR, Kalanthi P, Espina L, Comprecht RF: Use of phentolamine in acute myocardial infarction. Am Heart J 88: 144, 1974

13. Gold HK, Leinbach RG, Sanders CA: Use of sublingual nitroglycerin in congestive heart failure following acute myocardial infarction. Circulation 46: 839, 1972

14. Williams DO, Amsterdam EA, Mason DT: Hemodynamic effects of nitroglycerin in acute myocardia! infarction. Decrease in ventricular preload at the expense of cardiac output. Circulation 51: 421, 1975

15. Flaherty JT, Reid PR, Kelly DT, Taylor DR, Weisfeldt ML, Pitt B: Intravenous nitroglycerin in acute myocardial infarction. Circulation 51: 132, 1975

16. Baxter RH, Trait CM, McGuinness JB: Vasodilator therapy in acute myocardial infarction. Use of sublingual isosorbide dinitrate. Brit Heart J 39: 1067, 1977

17. Mifune J, Kuramoto K, Ueda K, Matsushita S, Kuwajima I, Sakai M, Takayanagi K, Murakami M: Hemodynamic comparisons between oral and sublingual isosorbide dinitrate in heart failure (abstr). Jap Circulat J 41: 623, 1977

18. Elkayam U, Rotmensch HH, Terdiman R, Geller E, Laniado S: Hemodynamic effects of chlorpromazine in patients with acute myocardial infarction and pump failure. Chest 72: 623,1977

19. Mifune J, Kuramoto K, Ueda K, Matsushita S, Kuwajima I, Sakai M, Iwasaki T, Inoue H, Shinagawa T, Murakami M: Treatment of acute left-sided heart failure with intramuscular injection of chlorpromazine. Jap Heart $\mathbf{J}$ 20:33, 1979

20. Chatterjee K, Parmley WW, Ganz W, Forrester J, Walinsky P, Grexello C, Swan HJC: Hemodynamic and metabolic responses to vasodilator therapy in acute myocardial infarction. Circulation 48: 1183, 1973

21. Shell WE, Subel BE: Protection of jeopardized ischemic myocardium by reduction of ventricular afterload. New Engl J Med 291: 481, 1974

22. Daluz PL, Forrester JS, Wyatt HL, Tyberg JV, Chagrasulis R, Parmley WW, Swan HJC: Hemodynamic and metabolic effects of sodium nitroprusside on the performance and metabolism of regional ischemic myocardium. Circulation 52: 400, 1975

23. Borer JS, Redwood DR, Levitt B, Cagin N, Bianchi C, Vallin H, Epstein SE: Reduction of myocardial ischemia with nitroglycerin or nitroglycerin plus phenylephrine administered during acute myocardial infarction. New Engl J Med 293: 1008, 1975

24. Chiarello $\mathrm{M}$, Gold HK, Leinbach $\mathrm{RC}_{4}$, Davis MA, Maroko PR: Comparison between the effects of nitroprusside and nitroglycerin and ischemic injury during acute myocardial infarction. Circulation 54: 766, 1976

25. Tift MB, Holman L, Green LH, Phillips DA, Markis JE, Cohn PF: Effect of nitroprusside on regional blood flow, and comparison with nitroglycerin in patients with coronary artery 
disease (abstr). Circulation $55 \& 56$ (Suppl): III-33, 1977

26. Morrison J, Binder A, Padnick M, Rubin K, Pizzarello R, Gulotta S: Isosorbide dinitrate and predicted myocardial infarct size in man (abstr). Clin Res: 25: 239A, 1977

27. Pagani M, Vatner SF, Braunwald E: Hemodynamic effects of intravenous sodium nitroprusside in conscious dog. Circulation 57: 144, 1978

28. DeMaria AAN, Amsterdam EA, Mason DT: Importance of maintaining systemic blood pressure during nitoglycerin administration for reducing ischemic injury in patients with coronary disease. Am J Cardiol 40: 504, 1977

29. Chatterjee K, Massie B, Rubin S, Gelberg H, Brundage BH, Ports TA: Long-term outpatient vasodilator therapy of congestive heart failure. Consideration of agents at rest and during exercise. Am J Med 65: 134, 1978

30. Awan NA, Miller RR, DeMaria AN, Maxwell KS, Newman A, Mason DT: Efficacy of ambulatory systemic vasodilator therapy with oral prazosin in chronic refractory heart failure. Circulation 56: 346,1977

31. Williams BO, Begg TB, Semple T, McGuinness JB: The elderly in a coronary care. Brit Med J 2: 451, 1976

32. Ueda K, Sugiura M, Hiraoka K, Mifune J, Ohkawa S, Murakami M, Matsuda T: A clinical study on acute myocardial infarction complicating disseminated intravascular coagulation. Jap J Geriat 15: 228, 1978 